\title{
OUR EXPERIENCES WITH THE TREATMENT OF PERIPROSTHETIC FRACTURES OF FEMUR
}

\author{
Leopold Pleva, Milan Šír, Roman Madeja
}

Centre of Traumatology University Hospital Ostrava, Czech Republic

Received: March 25, 2004; Accepted: May 18, 2004

Key words: Periprosthetic fracture/Internal and external fixation/Clamp plates

In the statement authors want to draw attention to the possibilities of treatment of periprosthetic fractures of femur. They present their own experiences with the treatment of these fractures by using various types of internal and external fixation evaluated from 1996 to 2003. They present some less common types of internal fixation as e.g. fixation by clamp plates.

\section{PREFACE}

Change in lifestyle, increased age and development of endoprosthetics are connected with increased occurrence of periprosthetic fractures in recent years. First mentions of these fractures were published in seventies (Mc Elfresh) later then in eighties and nineties of last century (Culp) $)^{1}$. There were descriptions of several possibilities of treatment of these fractures including their complications.

Incidence of periprosthetic fractures after the application of the total arthroplasty varies. The incidence between $0.6-2.5 \%$ was described in cases of supracondylar fractures above the femoral component of knee arthroplasty ${ }^{2}$.

The creation of these fractures is preceded by accident (as in case of other fractures) or there is a slow process of bone corruption for various reasons. The fracture then is caused by minimal trauma. In many cases patient does not even mention the accident. The fracture turns up during a common activity.

The treatment of periprosthetic fractures depends on the type of fracture (comminutives etc), location - distance from arthroplasty and other factors (osteoporosis, general condition of patient). Generally we can divide methods of treatment to conservative and surgical - $70 \%$ success in both methods if correctly implemented ${ }^{3}$.

The plaster of Paris, skeletal traction or a combination of both can be used as a conservative method. Individual or fabricated orthesis can be used during after-treatment.

Concerning surgical method, the descriptions of practically all types of internal and external fixation or their combinations appear in specialized literature ${ }^{4}$.

\section{PATIENTS AND METHODS}

From 1996 to 2003, we treated 21 periprosthetic fractures of the femur at our Centre of Trau-matology
University Hospital Ostrava (Table 1). Some were after total hip arthroplasty, some after total knee arthroplasty (Table 2). In two cases, we used conservative method, in 19 cases we chose surgical method (Table 3).

Table 1. Patients 1996-2003.

\begin{tabular}{|l|c|}
\hline Number of periprostethic fractures & 21 \\
\hline Men & 7 \\
\hline Women & 14 \\
\hline Average age & 74 years \\
\hline Average period of hospitalization & 56 days \\
\hline Average period of treatment & 258 days \\
\hline
\end{tabular}

Table 2. Localisation of fractures.

\begin{tabular}{|l|c|}
\hline $\begin{array}{l}\text { Femur fractures under } \\
\text { arthroplasty of hip }\end{array}$ & $4 \mathrm{x}$ \\
\hline $\begin{array}{l}\text { Femur fractures } \\
\text { above arthroplasty of knee }\end{array}$ & $17 \mathrm{x}$ \\
\hline
\end{tabular}

Table 3. Method of treatment.

\begin{tabular}{|l|c|}
\hline Conservative treatment & $2 \mathrm{x}$ \\
\hline External fixation & $3 \mathrm{x}$ \\
\hline Internal fixation (plate) & $3 \mathrm{x}$ \\
\hline Internal fixation (nail) & $13 \mathrm{x}$ \\
\hline
\end{tabular}

In two cases we treated periprosthetic fractures above total knee arthroplasty using conservative technique. Two comminutive fractures were very close to femoral compo- 


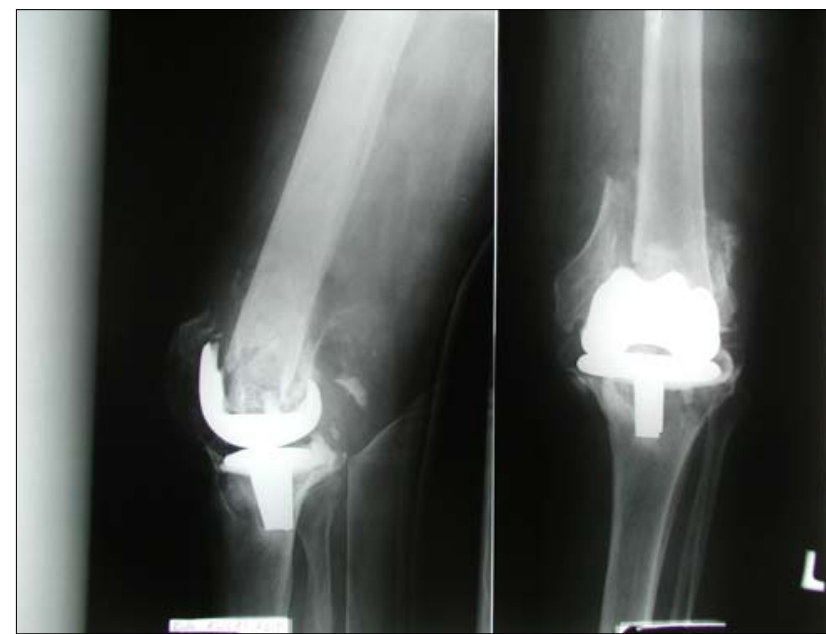

Fig. 1. Periprosthetic fracture of femur above the total knee arthroplasty treated by closed method (plaster of Paris)

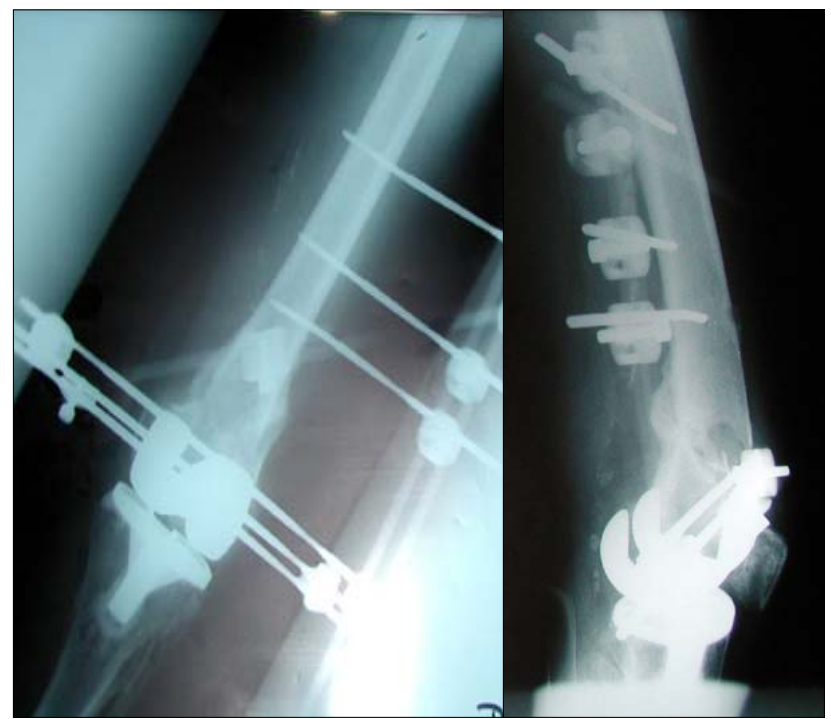

Fig. 3. Treatment of periprosthetic fracture of femur above the total knee arthroplasty by external frame fixation

nent of endoprosthesis of knee. We removed the plaster of Paris in 113 days at average (Fig. 1).

In three cases we treated fractures by external fixation, in one case external fixation of round type (Fig. 2), in two cases using external frame fixation (Fig. 3). We noticed no infectious complications during the treatment. We removed external fixation in 95 days at average (Fig. 4).

In thirteen cases of supracondylar fractures above the total knee arthroplasty we used intramedullary nailing. Time of hospitalization was 21 days at average, time of restoration to full weight bearing and mobility condition of limb before accident was 148 days at average (Fig. 5).

In one case we used plate osteosynthesis for treating the periprosthetic fracture after the application of hemiarthroplasty of the hipp (Fig. 6).

In two cases of periprosthetic fractures under the femoral component of total hip arthroplasty we used

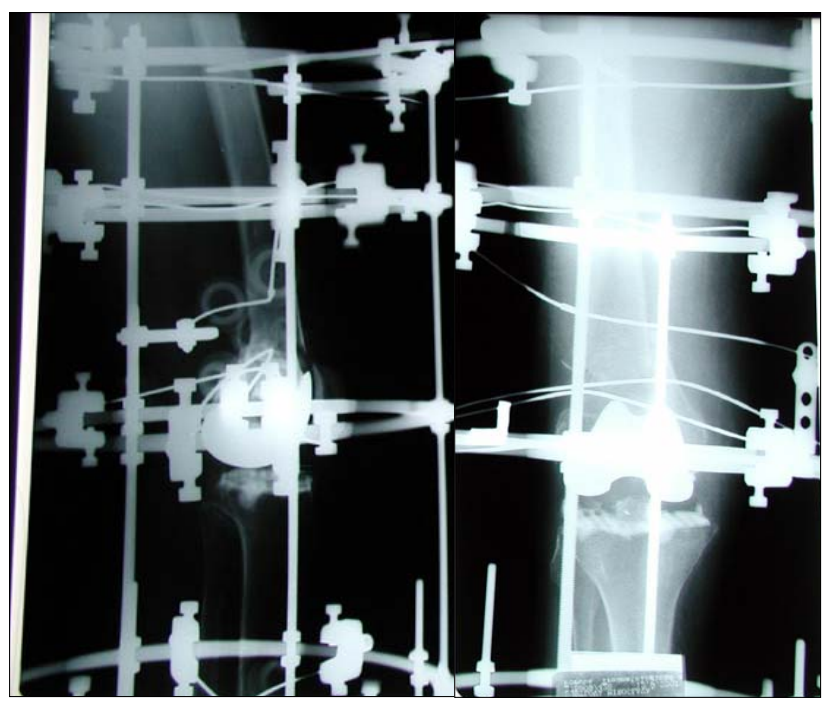

Fig. 2. Post-operativ X-ray after the external fixation of periprosthetic fracture above the knee arthroplasty

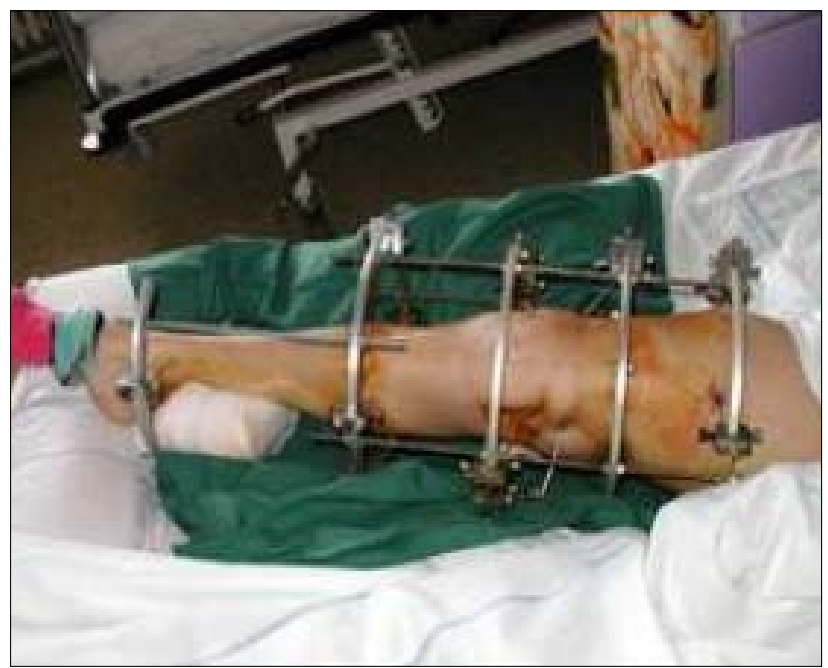

Fig. 4. Patient before removal of external fixation

internal fixation by clamp plates. This is a plate which consists of the first half part with holes for screws and second half part with caverns for bedding of the so called clamps. The plate and clamps are constructed in such a way as to allow using them for bone diaphysis as well as in the supracondylar area for asymmetrical construction of some clamps. Clamps allow fixation of the plate to the part of the bone in which the component of arthroplasty is intramedullary placed (Fig. 7-10).

During the following observation of the patients we did not notice any post-surgical complications. Average hospitalization time was 28 days. After the checkup after 3 months we have allowed gradual weight bearing. Hip mobility was restored to the original condition before the fracture (Fig. 11-13). 


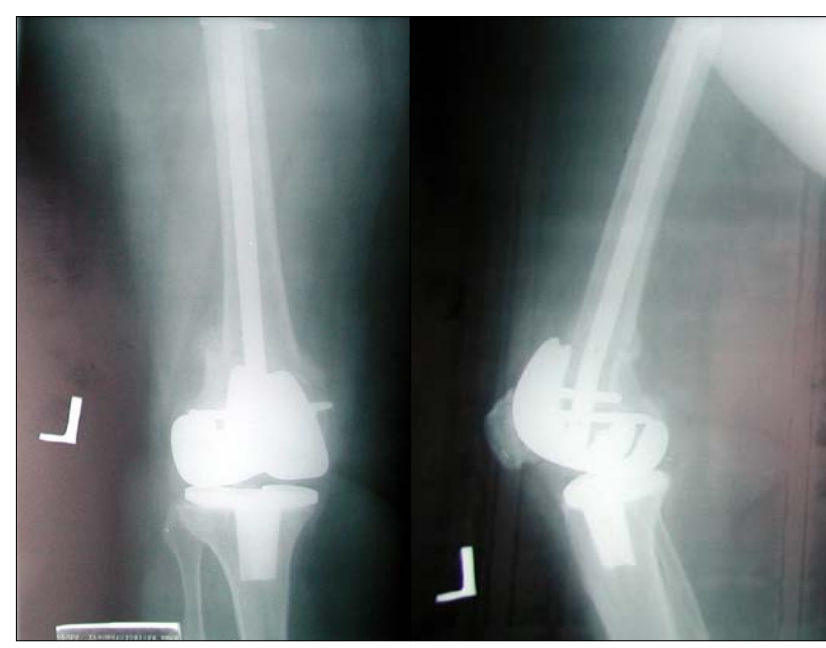

Fig. 5. Periprosthetic fracture above the total knee arthroplasty treated by intramedullary nailing

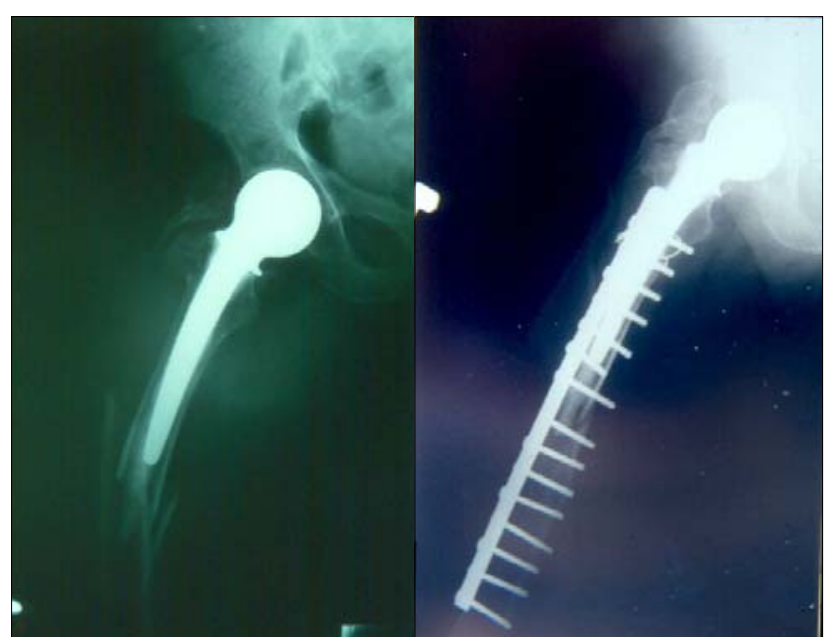

Fig. 6. Plate osteosynthesis of fracture under hemiarthroplasty of the hipp

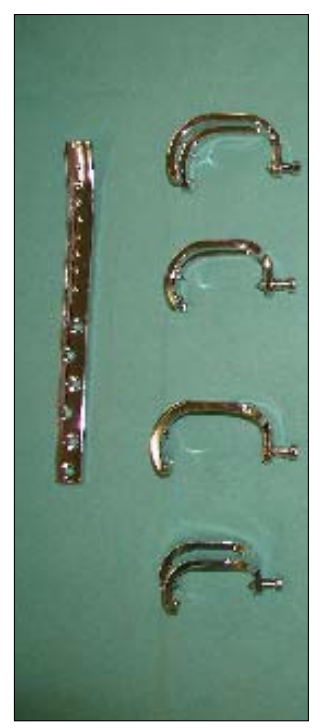

Fig. 7. Clamp plate

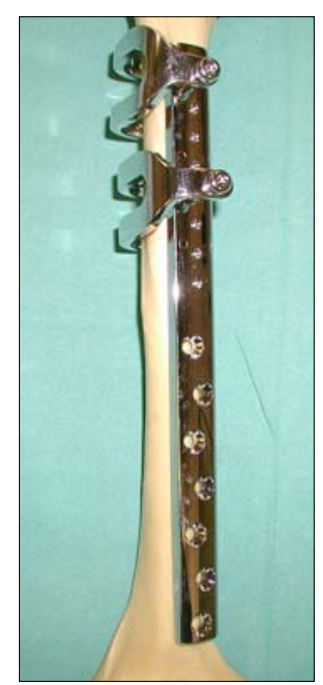

Fig. 9. Clamp plate

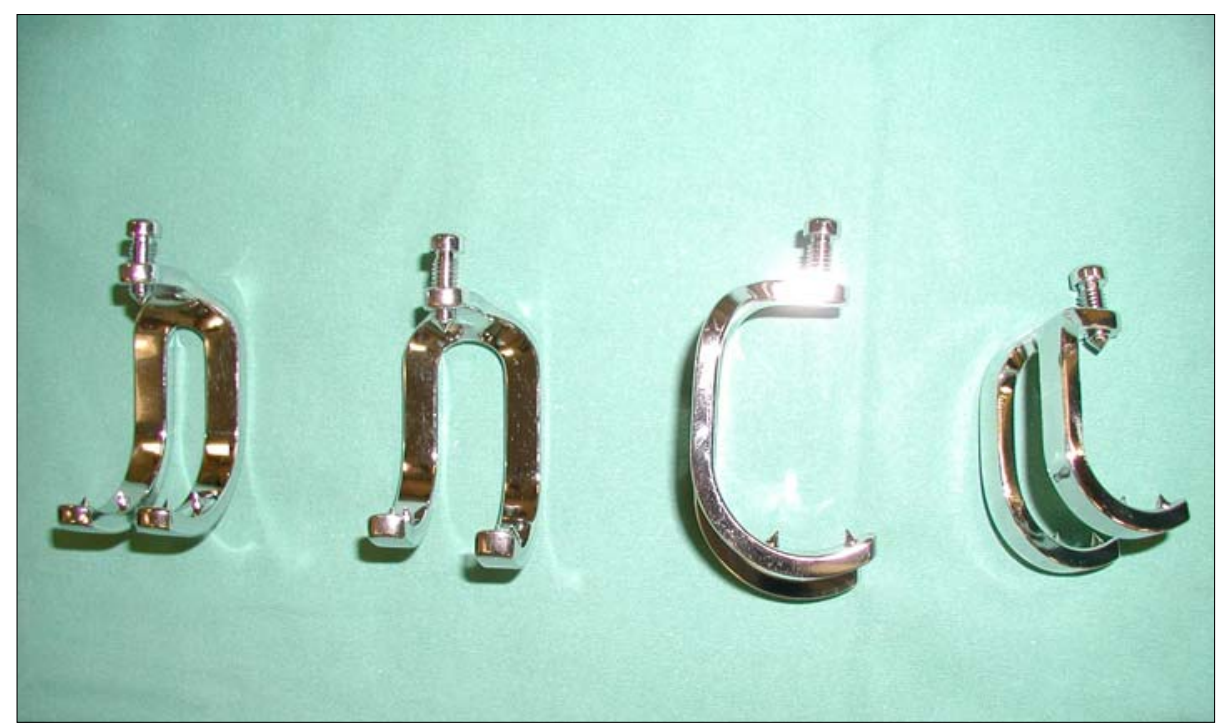

Fig. 8. Clamp in Detail

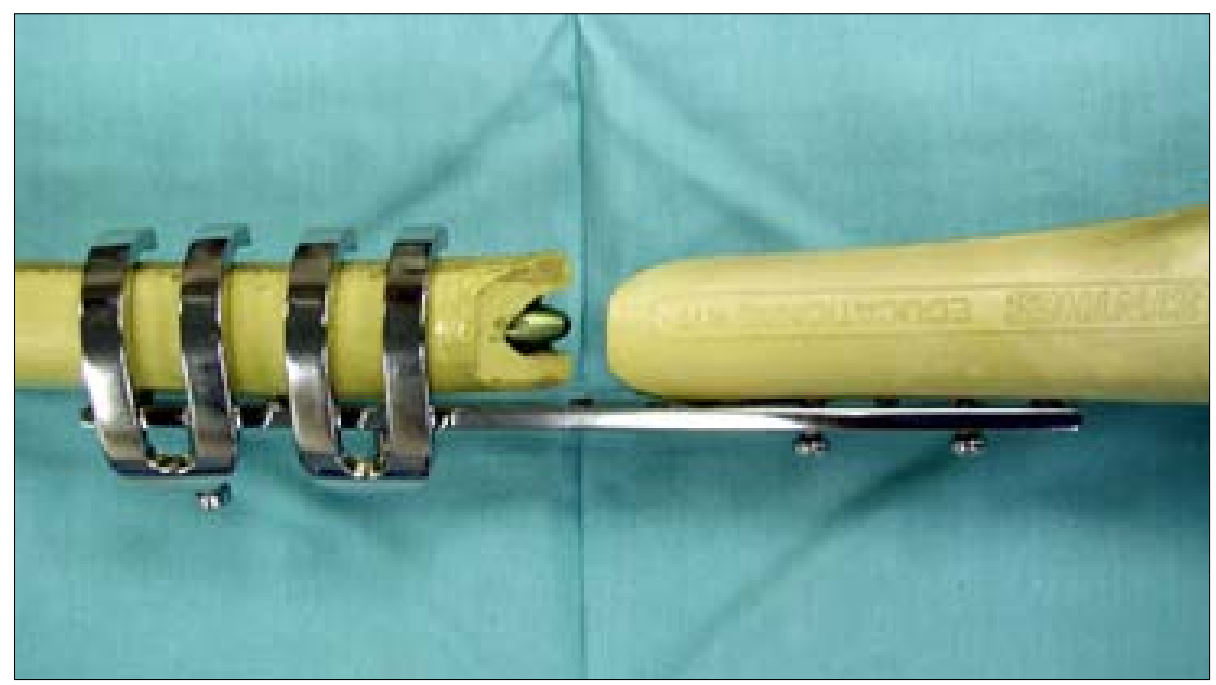

Fig. 10. Model of internal fixation by clamp plate on the bone model 


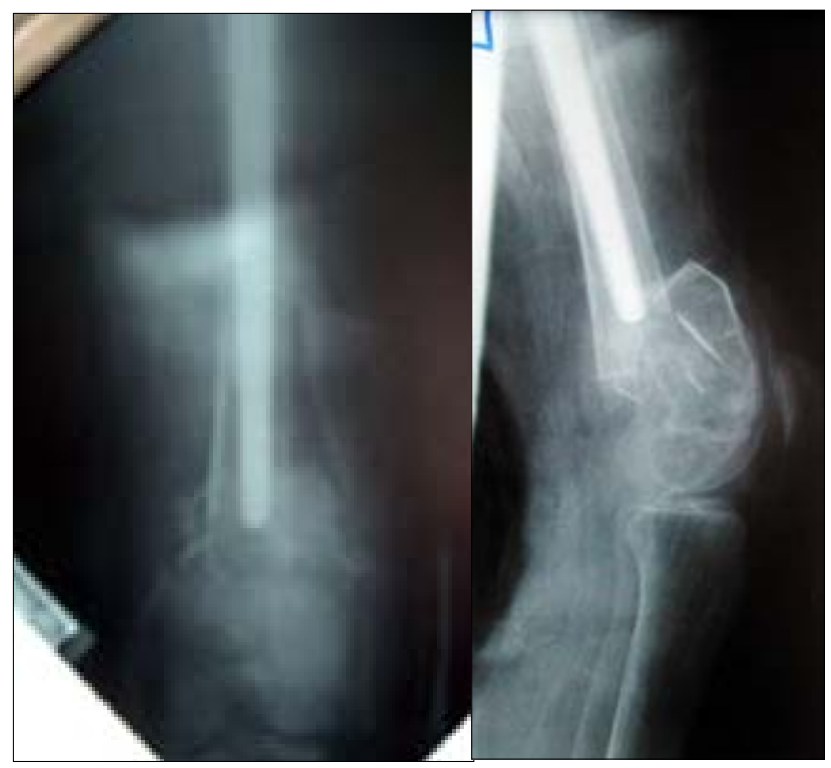

Fig. 11. Supracondylar fracture under long femoral component of total hip arthroplasty

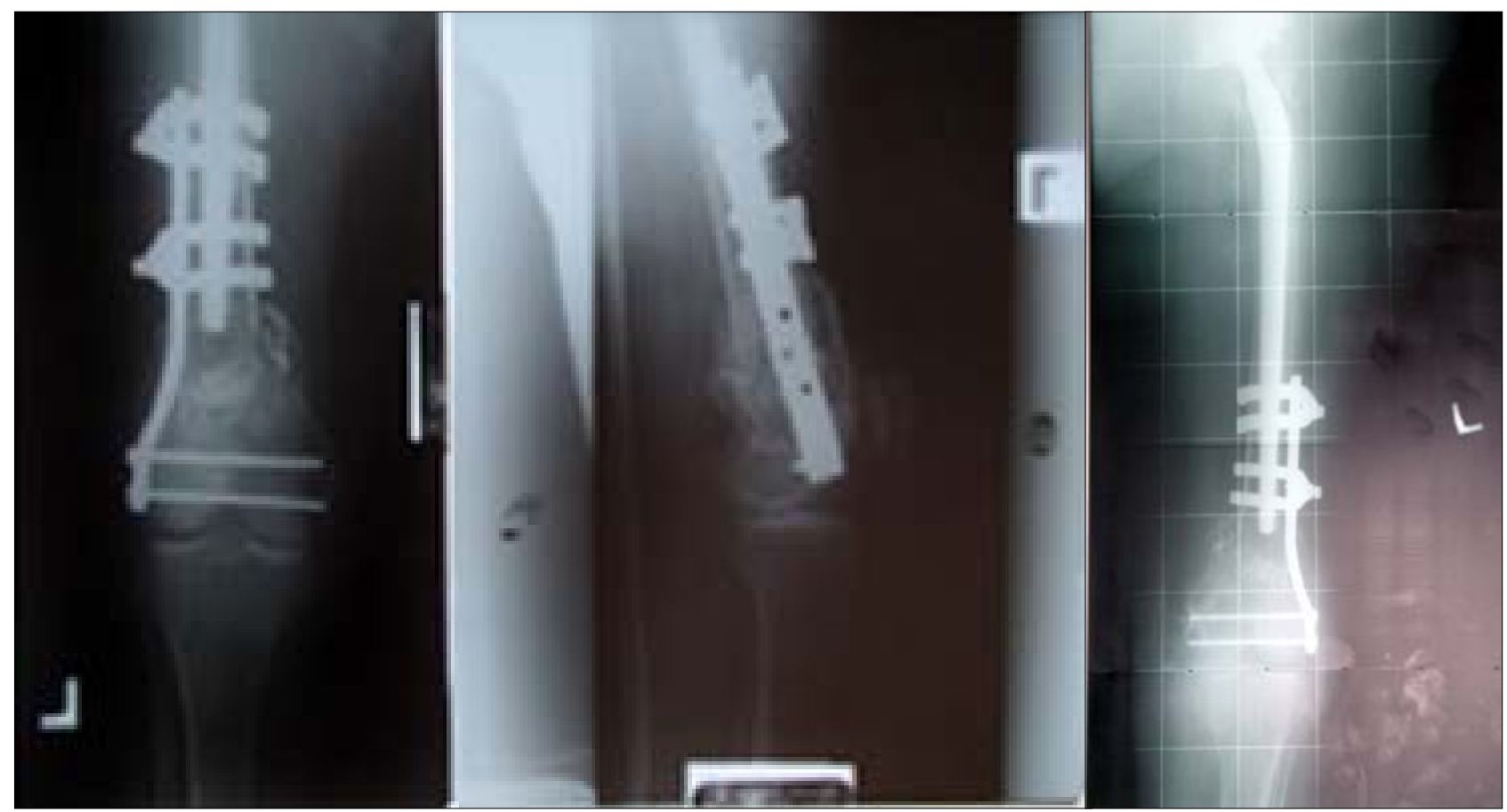

Fig. 12. X-ray after the internal fixation

\section{DISCUSSION}

Periprosthetic fractures make an important therapeutical problem for their individual and specific character. Their diversity from other types of fractures consists in the fact that they are fractures of bone with the implants of total arthroplasty and therefore the method of treatment must often be different from therapeutical as in case of other types of fractures. Among the general risk factors we can include osteoporosis, rheumatoid arthritis, treatment with corticosteroids and naturally other diseases which may affect healing processes of patients. Emergence of these fractures can be additionally caused by technical problems e.g. anterior notching of the femoral cortex of total knee arthroplasty ${ }^{2}$, damage of proximal femur at application of the total hip arthroplasty and other ${ }^{3,5}$. Among other possible complications there can be postoperative treatment and patient's personality - early weight bearing. The complications may occur at conservative treatment as well as after the surgical treatment and they are affected 

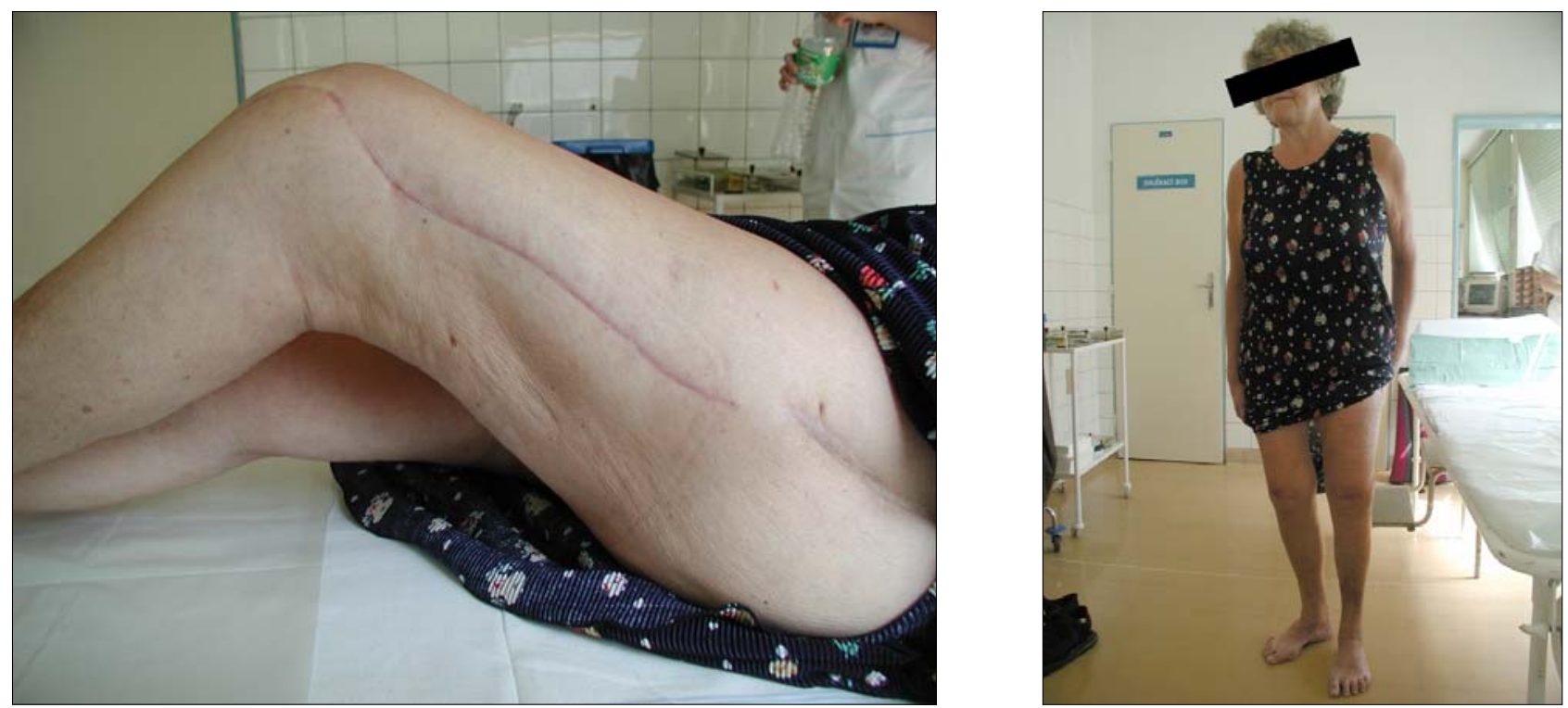

Fig. 13. Patient 3 months after the operation

by right evaluation of fracture and right choice of the treatment method and also by the patient preparation and leading of the treatment including rehabilitation and weight bearing.

\section{CONCLUSION}

In our announcement we wanted to draw attention to possibilities of treatment of peri-prosthetic fractures of femur after the application total knee arthroplasty as well as after the total hip arthroplasty. We present our patients and our own experiences with the treatment of these complicated fractures. We have pointed out some less common type of internal fixation (clamp plate).

\section{REFERENCES}

1. Culpulp RW, Schmidt RG, Hanks G et al. (1987) Supracondylar fracture of the femur following prosthetic knee arthroplasty. Clin Orthop 222, 212-222.

2. Figgie MP, Golberg VM, Figgie HE et al. (1990) The results of treatment of supracondylar fracture above total knee arthroplasty. J Arthroplasty 5, 267-276.

3. Johansson JE, McBroom R, Barrington TW et al. (1981) Fracture of the ipsilateral femur in patients with total hip replacement. Am J Surg 63, 1435-1442.

4. Pleva L. Zevní fixace v traumatologii. Ostrava: Cicero, 1992. $173 \mathrm{~s}$.

5. Shaw JA, Greer RB III. Orthopaedic Surgery. $3^{\text {rd }}$ ed. Philadelphia, Pa: JB Lippincott, 1994. 1056 s. 